\title{
Violência Contemporânea e Penas
}

\author{
Henny Goulart \\ Professora Adjunta de Direito Penal \\ da Faculdade de Direito da Universidade \\ de São Paulo
}

É comum falar-se, atualmente, em aumento da violência, com referência aos altos índices de criminalidade, e sua maior gravidade, principalmente nos grandes centros.

$\mathrm{Na}$ verdade, o progresso alcançado pela humanidade nos últimos séculos, em todos os setores de atividade, trouxe nítidas vantagens para a saúde, instrução, comunicação e demais campos onde se desenvolve o atuar humano; por outro lado, esse mesmo progresso deslocou massas imensas do viver tranqüilo dos campos para as gigantescas cidades modernas, onde a vida se desenvolve de forma tensa, na luta diária no trabalho, na preocupação constante da manutenção da família, na competição acirrada pela escalada social, no desafio enfim para a realização das potencialidades de cada um.

Realmente, se lembramos o viver dos povos primitivos, verificaremos de imediato o contraste marcante em relação aos nossos dias: a terra era a base da vida, desenvolvendo a família, nas pequenas aldeias, a divisão simples dos trabalhos e mantendo juntos os seus membros, em rígida estrutura, cultura e religião próprias. As classes que daí surgiram eram claramente definidas e o nascer determinava, imediatamente, o tipo de vida que cada pessoa teria.

A revolução industrial trouxe o sentido de mudanças inevitáveis: os novos tipos de trabalho que deviam ser aprendidos, os novos locais onde morar, a troca da amplidão dos campos para os recintos fechados e enfumaçados das fábricas, a perda da presença constante dos familiares, com a deslocação da produção econômica fechada, como uma unidade, para o trabalho fora, o sentimento de poder ganhar mais por si mesmo desatando as ambições e trazendo formas desconhecidas de conflitos, com a paulatina redução da autoridade patriarcal, tudo fazendo com que as funções básicas da família fossem modificadas ou reduzidas em favor de instituições sociais novas, como as escolas, locais de diversão, etc.

No nosso século, principalmente nas últimas décadas, por imposição das novas necessidades trazidas pelo progresso, pelos abalos e mudanças das estruturas políticas e econômicas que têm percorrido 
o mundo, as migrações para as grandes cidades aumentaram e as famílias, que de uma forma geral vêm se tornando menores, já não podem em sua grande maioria oferecer aos seus membros a tranqüilidade e a segurança do passado.

O ser humano hoje vive quase sempre tenso pelas dificuldades de realização pessoal. O mais certo, porém, seria dizer que essa tensão surgiu e vem há muito aumentando em razão das profundas transformações nas estruturas institucionais das sociedades, das ideologias conflitantes, sempre existentes mas hoje avivadas nos debates mundiais, nas guerras em várias partes do mundo e nos atentados terroristas, das necessidades do desenvolvimento econômico, social e político e, mais diretamente, em razão do combate diário em cada setor, onde a concorrência está sempre presente, tudo, enfim, colaborando para o aumento das pressões a cada um é submetido.

É por isso que autores, como o americano Alvin Toffler, afirmam que o fenômeno do choque cultural e dos efeitos da revolução tecnológica que estamos vivendo seria o responsável pela maior parte do espanto, da frustração e desorientação das pessoas hoje em dia, pois essas mudanças assinalariam uma nítida ruptura com toda a experiência passada do homem e teriam um impacto terrível nos hábitos, crenças e auto-imagem de milhões de pessoas. Por outro lado, o ritmo acelerado da invenção, exploração e difusão, por sua vez movimentaria ainda mais todo o sistema e esse crescente índice de transformações no mundo que nos cerca conturbaria o nosso equilíbrio interno e alteraria a própria maneira de olhar a realidade. Assim, a aceleração que se nota no exterior, produziria uma aceleração no nosso mundo interior, influenciando profundamente o comportamento humano e provocando fortes e contrastantes reações nas diferentes pessoas.

Neste panorama, e pela influência ou de fatores endógenos ou pessoais, encontrados na constituição biopsíquica dos indivíduos, ou de fatores ambientais, decorrentes das dificuldades encontradas no meio social, com referência à família, à escola, ao trabalho, às migrações e ao relacionamento, é que podemos encontrar as causas do aumento da criminalidade.

Se é verdade que o crime sempre existiu, o que chama a atenção na atualidade é o crescimento da criminalidade, que passou dos índices considerados aceitáveis em qualquer sociedade, para marcas sem precedentes. Por outro lado, esse aumento foi sendo acompanhado pela violência contra as pessoas, multiplicando-se os latrocínios, seqüestros, etc.

Isso não significa que os crimes não violentos, como o furto, tenham desaparecido ou diminuído. As notícias nos dão conta de que, em relação a 1982, dobrou o número dos furtos que teria passado de 40.000 em $1983^{1}$.

1. "Folha de São Paulo", de 19 de fevereiro de 1984. 
Deve-se notar também que os jovens adultos delinqüentes respondem pela maior parcela desse aumento, na quantidade e gravidade dos crimes. E a participação feminina também está em alta.

Embora a criminalidade violenta possa ser encontrada em qualquer grande cidade do mundo, não se pode deixar de constatar o seu crescimento nas grandes cidades brasileiras, espraiando-se, já, embora em menor número, para as cidades do interior, balneários, etc., com a mesma violência.

Entendemos que muitos fatores são os responsáveis por esse quadro: o crescente desemprego, o alto índice da inflação com o conseqüente mas desmedido aumento de todos os produtos, serviços, prestações e taxas; o pouco e, em muitos casos, nenhum respeito aos direitos mais comezinhos dos cidadãos; a violência policial que, em tantos e famosos casos, deu mostras da sua arbitrariedade e desconhecimento ou pouco caso da lei; e a difícil, lenta e cara justiça que, pela sua estrutura antiquada e falta de recursos financeiros adequados, não tem sido capaz de corresponder plenamente aos anseios de tantos espoliados e injustiçados - todos esses fatores respondem, evidentemente, pelas tensões, frustrações, desesperos, desejos de vingança, ou procura de justiça pelas próprias mãos, que acabam por se transformar em atos criminosos.

Nesta situação, o cotidiano das pessoas vem mudando: todos tomam mais cuidado, a desconfiança está sempre presente, evita-se tanto quanto possivel sair a noite ou passar por lugares isolados, as pessoas se armam, cercam-se as residências de apetrechos de segurança, guardas particulares são contratados, tudo a mostrar o sentimento de insegurança que domina a população ante a rotina diária dos atos criminosos violentos, mostrados e ressaltados pelos meios de comunicação.

Traumatizadas e sentindo-se impotentes para reagir ou estancar a onda de criminalidade, muitas pessoas voltam a falar em repressão também violenta, com inclusão da pena de morte na legislação penal e redução da idade de 18 para 16 anos para a responsabilidade.

Durante séculos, as antigas legislações aplicaram aos criminosos castigos corporais cruéis, trabalhos forçados nas minas e galés, exílio e a pena de morte.

Tendo por finalidade causar sofrimento ao condenado, fazendo-o expiar pela dor o crime cometido, os códigos mais antigos previam os castigos corporais, tidos como penas de grande importância e aplicados em variadas modalidades. No período da Idade Média, segundo Cuello Calon, a crueldade e extensão das penas corporais aumentam, inventando-se novos métodos para fazer sofrer o condenado. Nos séculos seguintes, na Alemanha, França e Espanha, as mutilações, os 
açoites e a marca de ferro quente foram comuns e prodigamente usados. Alguns desses castigos tiveram aplicação até o século passado ${ }^{2}$.

Defendidas como um dos melhores meios de intimidação e adequado castigo para os culpados de crimes brutais, reveladores de ausência de sentimentos humanitários pois, sendo sua execução rápida e dolorosa, elimina os inconvenientes da pena privativa da liberdade; preconizadas também como meio educativo, principalmente com relação aos menores, e como providência enérgica capaz de refrear certas tendências criminosas, tem sido invocado em seu abono o exemplo da Inglaterra onde, até a primeira metade do século XIX empregava-se o castigo corporal, restrito aos condenados masculinos maiores de 16 anos, em razão do "Criminal Law Consolitation Act", de 1861. Mais tarde ficaram sujeitos a essa pena os autores de roubo e tentativa de morte. Em 1913, a Câmara dos Comuns adotou a fustigação para os proxenetas. A partir daí, a escala de aplicação da pena corporal foi sendo sensivelmente reduzida, até sua abolição.

Nos Estados Unidos, por diversas vezes, na imprensa e nos debates parlamentares, foi pedida a aprovação de castigos corporais, principalmente para o "kidnapping", seqüestro de menores, mas os projetos não tiveram sucesso.

Os sentimentos de humanidade e de respeito à dignidade do ser humano, ínsitos nas Declarações de Direitos do Homem aceitas pelos países civilizados vieram, todavia, repudiar de vez essas penas expiativas e degradantes como de nenhuma utilidade para reduzir a criminalidade, servindo apenas para revoltar os pacientes, prejudicar-lhes a saúde, quando não para torná-los física e mentalmente inúteis sociais. Na realidade, as penas corporais não mudam os sentimentos das pessoas, não extinguem ou reduzem a criminalidade, constituindo aberração sob qualquer dos seus aspectos, como penalidade principal ou complementar. Até como medida disciplinar nas prisões, sua aplicação está totalmente condenada. Continuam, entretanto, a serem ilegalmente usadas em muitos institutos penais, sendo comum também ainda hoje nas delegacias de polícia, para obtenção de confissões, aplicadas por sádicos agentes, para os quais o que conta é a rapidez e a promoção pessoal quanto à solução dos delitos, não importando muito quem seja o verdadeiro criminoso.

Quanto à pena de morte foram, igualmente, usadas durante séculos. Imposta para a maioria dos crimes era, geralmente, precedida de tormentos e mutilações e sua execução, sempre pública, se realizava através de diversas e bárbaras modalidades, como esquartejamento, imersão, fogueira, garrote, crucificação, decaptação e outras. A Idade Média manteve a pena de morte e a crueldade dos meios de tortura, sendo que a Inquisição registra a seu débito milhares de execuções, na fogueira ou por estrangulamento.

2. Cuello Calon, Eugenio, Derecho Penal, Bosch Casa Edit., Barcelona, 1945, pág8. e 247. 
A partir do século XVIII, a corrente contrária à sua manutenção firma-se cada vez mais, transformando-se em declarada campanha no século passado e, sempre com força vai conseguindo, principalmente após a segunda grande guerra, reduzir não só os casos de aplicação, mas também o número das execuções programadas, pelo exercício do indulto ou da comutação. Os resultados obtidos, primeiramente na Inglaterra, acabaram por reforçar as campanhas em curso em outros países, como ocorreu na Alemanha, Itália, França e Estados Unidos, além da América Latina, conseguindo sua abolição ou redução, até que a pena capital ficou mantida em algumas poucas legislações. Restou, no entanto, a tradição no sentido de sua manutenção nas legislações militares em tempo de guerra.

No Brasil, o Livro V das Ordenações Filipinas impunham, com largueza, a pena de morte precedida, em muitos casos, de tortura. Cominavam também extensamente as penas corporais.

Foi a Constituição de 25 de Março de 1824 que, primeiramente, fixou entre nós princípios que consagravam o respeito aos direitos e liberdades individuais, entre os quais lei igual para todos, proibição de açoites, tortura, marca de ferro quente e todas as demais penas cruéis, abolindo também o confisco de bens.

O nosso primeiro Código Penal, de 1830, estabelecia penas ainda rigorosas, como as de galés, prisão com trabalhos, banimento, além da pena de morte pela forca (art. 38), cominada aos crimes de insurreição, pela reunião de vinte ou mais escravos para haverem a liberdade pela força (art. 113), homicídio agravado (art. 192) e latrocínio (art. 271). Posteriormente, em 1835, a pena de morte foi estendida aos escravos que matassem, envenenassem ou ferissem gravemente ao seu senhor, feitor, ou familiares destes. A partir de 1855, embora continuasse inscrita no texto legal, a pena de morte não mais foi executada, muito contribuindo para isso o erro judiciário que levou ao patíbulo o fazendeiro Manuel Mota Coqueiro, pela suposta morte de um colono e sua família. D. Pedro II, considerando o abalo produzido na opinião pública, passou a comutá-la sistematicamente para a de galés, apegando-se a qualquer circunstância favorável ao réu ${ }^{3}$.

Com a proclamação da República o decreto 774, de 29 de setembro de 1890 extinguiu a pena de morte. Assim, o Código Penal de 1890 não a incluiu no elenco de penas do seu artigo 43, enquanto o artigo 44 era expresso ao afirmar não haver mais penas infamantes.

A Constituição de 24 de fevereiro de 1891, abolindo expressamente as penas de galés e de banimento, dispôs expressamente que abolida ficaria também a pena de morte, ressalvando as disposições da legislação militar em tempo de guerra (art. $72, \S \S 21$ e 22). E a Constituição de 16 de julho de 1934 manteve a mesma orientação.

3. "Pena de Morte no Brasil", Revista Brasileira de Criminologia e Direito Penal, no 177, abril/junho de 1967, pags. 7/20. 
A pena de morte volta a surgir no Brasil com a Carta autoritária de 1937. O seu artigo 122, $\mathrm{n}^{\circ} 13$, com a emenda da Lei Constitucional $\mathrm{n}^{\circ} 1$, de 16 de maio de 1938, fixou-a para as hipóteses de tentativa contra a soberania da nação, de insurreição armada contra os poderes do Estado, a prática de atos destinados a provocar a guerra civil, suscitar terror, ou atos contra a vida, a incolumidade ou a liberdade do presidente da República, além dos casos de homicídio cometido por motivo fútil ou com extremos de perversidade.

O novo Código Penal, de 1940, a exemplo do anterior, não estabeleceu a pena de morte, consignando apenas as de prisão e multa.

A Constituição de 18 de setembro de 1946 manteve, praticamente, os termos da Constituição liberal de 1934, ao dispor sobre a matéria em seu artigo 141, §31. O mesmo se pode dizer sobre a Constituição de 24 de janeiro de 1967, em seu artigo 150, § 11 .

A Emenda Constitucional $\mathrm{n}^{\circ}$ 1, de 17 de outubro de 1968, embora declarando de forma genérica não haver pena de morte, de prisão perpétua, de banimento ou confisco, excetuou no artigo 153, §11, os casos de guerra externa, psicológica adversa ou revolucionária ou subversiva, "nos termos que a lei determinar". Isto porque, em decorrência do Ato Institucional $\mathrm{n}^{\circ} 14$, de 5 de setembro de 1969, estava em vigor o decreto-lei 898, de 29 do mesmo mês e ano, definindo os crimes contra a segurança nacional e a ordem política e social impondo, em numerosos casos, a pena de morte. Na prática, todavia, não houve nenhuma execução legal.

Mas era preciso extirpar essa pena mesmo da legislação excepcional. Isto foi feito pela Emenda Constitucional $\mathrm{n}^{\circ}$ 11, de 13 de outubro de 1978, dando nova redação ao $§ 11$ do artigo 153 da Emenda $\mathrm{n}^{\circ}$ 1, citada. A nova redação estipulou "não haverá pena de morte, de prisão perpétua, nem de banimento. Quanto à pena de morte, fica ressalvada a legislação penal aplicável em caso de guerra externa". Dessa forma, sobreveio nova lei de segurança nacional, $\mathrm{n}^{\circ} 6.620$, de 17 de dezembro de 1978, trazendo em seu catálogo de crimes somente apena de prisão. E a lei de segurança em vigor, 7.170, de 14-12-83, manteve a mesma orientação.

Nessas condições, a pena de morte permanece inscrita apenas na legislação militar, para os crimes praticados por militares ou civis em tempo de guerra. Assim foi estabelecida no chamado Código Penal da Armada, decreto $\mathrm{n}^{\circ}$ 18, de 7 de março de 1891, estendido ao Exército pela lei 612 , de 29 de setembro de 1899. Da mesma forma, no Código Penal Militar promulgado pelo decreto 6.227, de 24 de janeiro de 1944 e, no atual, decreto-lei 1.001, de 21 de outubro de 1969. Aqui, também vamos encontrar no Livro $I I$, que cuida dos crimes militares em tempo de guerra, a cominação da pena capital, no grau máximo, a numerosas figuras como traição, favorecimento ao inimigo, coação a comandante, informação ou auxílio ao inimigo, covardia, espionagem, motim, revolta ou conspiração, rendição ou capitulação, etc. aplican- 
do-se, da mesma forma, ao agente de homicídio qualificado em presença do inimigo, genocídio em zona militarmente ocupada, roubo, extorsão e saque em zona de operações militares ou em território militarmente ocupado, rapto e violência carnal em local de efetivas operações militares. O fuzilamento é a forma prescrita.

Em todos esses casos, a pena de morte apresenta a justificativa da excepcionalidade da situação.

Foi sempre alegado, em favor da pena de morte, que: acautela com maior segurança o interesse da sociedade; é a única que realmente elimina o problema, pois a prisão não livra a comunidade do delinqüente, que a ela volta, apresentando o mesmo ou maior perigo; representa excelente meio de expurgar a sociedade dos seres inadaptáveis e dos autores de crimes hediondos; e sendo grande o seu poder intimidativo, acentuado pela publicidade de sua pública execução, atua como elemento dissuasivo, reduzindo a criminalidade.

Entendemos que o maior interesse de qualquer sociedade deve ser o desenvolvimento e progresso pacífico de seus cidadãos, de cuja força de trabalho, inteligência e dedicação precisa para manter-se e ser respeitada entre as nações. $O$ aumento de criminalidade ocorre quando as possibilidades normais de vida social não existem, ou são diminutas, ou seja, quando as oportunidades de desenvolvimento da personalidade de cada um são truncadas ou sensivelmente reduzidas, frustrando-se o anseio natural do ser humano de realizar-se, pela vida em família, pela educação, pelo trabalho, pelo contínuo progredir pessoal na procura das metas desejadas. Para que haja normalidade social é preciso que o Estado coloque, no primeiro lugar das suas preocupações e diretrizes, o ser humano e suas necessidades.

Quanto ao segundo argumento, é verdade que a pena de prisão não revolveu, e talvez nunca revolverá, o problema da criminalidade. Está há muito provado que não é meio capaz de reeducar ou promover a readaptação social da maioria dos criminosos, não pela prisão em si mesma, mas pela falta de institutos, pessoal e tratamento adequados. Como executada hoje, a pena de prisão representa apenas o afastamento do condenado do âmbito social, durante o período da condenação, período que traz relativa tranqüilidade aos demais cidadãos. Relativa porque todos sabem que o condenado pode fugir ou, cumprida sua condenação, ou beneficiado pelo indulto, comutação, prisão albergue ou livramento condicional, vai voltar. E geralmente volta pior: ou revoltado, porque não teve uma defesa eficaz, ou cumpriu a condenação em condições subumanas; ou mais profissional no crime, porque teve oportunidade de aprender muito com os colegas mais perigosos e adestrados.

Como bem afirma Heleno C. Fragoso, o Código Penal funciona praticamente para os pobres e deserdados da sorte ${ }^{4}$. Quem pode paga

4. Direito Penal e Direitos Humanos, Editora Forense, Rio de Janeiro, 1977. 
bons advogados, conta com elogiosos testemunhos e usa de todos os recursos legais. O pobre, que constitui a maior parte da nossa população, contará apenas com uma pobre defesa dativa que, na maioria dos casos, não vai além da primeira instância. $\mathrm{E}$ a condenação é geralmente inevitável. Por outro lado, as críticas ao nosso chamado "sistema penitenciário" acumulam-se há anos, sem que qualquer providência concreta tenha sido tomada pelas autoridades para estabelecer, realmente, um sistema, com filosofia moderna da pena utilitária, onde a cela individual, o trabalho obrigatório, a reeducação e o tratamento médico especializado, se tornem as bases para a procura da readaptação social dos delinqüentes perigosos, estabelecendo-se no Código Penal maior número e diversidade de substitutivos penais para os não perigosos, que possam efetivamente ser praticados pelas mudanças administrativas e contratação de pessoal indispensáveis. Com isso, além da construção dos institutos próprios, certamente se reduziria substancialmente a população carcerária da maioria dos presídios os quais, como grandes cidades à parte, apenas mantêm amontoados os seus prisioneiros, sem trabalho ou qualquer tipo de tratamento, excluída toda a dignidade de um verdadeiro viver, com os resultados desastrosos que todos conhecemos, como motins, fugas, brigas e assassinatos entre os presos, e nenhuma forma de recuperação.

Continuamos a não acreditar em seres indaptáveis. Os progressos da ciência em todas as áreas são inegáveis e continuam apresentando novas soluções. O que precisamos é do estabelecimento e manutenção dos institutos próprios e dos tratamentos adequados. $\mathbf{E}$ isso requer vultosas verbas, assim como investimentos enormes são necessários para a completa reestruturação de qualquer sistema penitenciário. E o Estado hoje, afogado na recessão e nas dívidas interna e externa, evidentemente prefere não pensar nisso.

$O$ poder intimidativo que muitos entendem como o melhor argumento da pena de morte, também não existe. Séculos de sua aplicação não fizeram desaparecer os crimes hediondos. Nem mesmo quando as execuções eram públicas. Como afirmou Beccaria, o rigor do castigo faz menor efeito sobre o espirito dos homens do que a duração da pena, pois a nossa sensibilidade é mais fácil e com mais constância atingida por uma impressão ligeira, porém freqüente, do que por um abalo violento, mas passageiro. Na verdade, os suplícios, pela sua continuidade, tornam-se apenas um espetáculo para a multidão que assiste. Foi o que ocorreu durante a Revolução francesa quando o povo reunido na praça pública se divertia, conversava $\mathrm{e}$ humilhava os condenados à guilhotina, na sua passagem para o patíbulo.

Atualmente, mesmo nos paises que ainda adotam a pena de morte, ou a restabeleceram, como alguns Estados americanos, usam-se métodos modernos, buscando-se uma execução rápida, com o menor sofrimento possivel para o condenado, dentro dos presídios, com assistência de poucas pessoas especialmente convidadas. E neste quadro, o poder intimidativo para a multidão não tem lugar. 
Mesmo assim, as críticas a essas execuções continuam, não só em razão da pena, mas principalmente em razão de alguns casos em que os condenados permaneceram durante longos anos no chamado "corredor da morte", sob medidas de estrita segurança, mas trabalhando ou estudando em suas celas, ou escrevendo livros que se tornaram sucesso, cumprindo, praticamente, uma severa pena de prisão, com bom comportamento para, afinal, serem levados à câmara de gás ou à cadeira elétrica, quando este ato final já não representava nenhum exemplo ou qualquer utilidade social.

Por fim, a possibilidade do erro judiciário, com a condenação do inocente, apesar das pretensas provas em contrário - como já ocorreu em outros países, em casos que ficaram famosos, persistindo até hoje dúvidas no espírito popular - torna a aplicação da pena de morte extremamente grave, porque absoluta.

Assim, não há argumento a favor da pena de morte que não conte hoje com boa argumentação contrária. Nenhuma das penas citadas, todas retributivas e expiatórias e em desacordo com a moderna doutrina penal, conseguiu extinguir a criminalidade em todos os séculos de vida comunitária. E nem conseguirá, porque os bons e maus sentimentos sempre estarão presentes e a humanidade continuará a percorrer o seu caminho presa às desavenças e descontroles sociais, normais porque as pessoas são diferentes e a convivência absolutamente pacífica será sempre difícil, requerendo autocontrole, educação, sentimento de respeito aos direitos dos outros, elementos ofuscados tantas vezes pela inveja, ódio, como pela paixão.

$O$ que se quer evitar é o aumento da criminalidade, em especial dos crimes com violência às pessoas, cuja continuidade e não identificação dos autores, quando a não prisão dos identificados, acaba por fixar no cenário social o sentimento perigoso da insegurança e, mais ainda, o descrédito quanto à eficiência das autoridades competentes, levando muitos a fazer justiça pelas próprias mãos, como tem ocorrido em tantos casos de linchamentos - pena de morte sem julgamento ou possibilidade de qualquer apelo - por não se acreditar mais que chamada, a polícia chegue em tempo, prenda os criminosos ou que a justiça faça a sua parte.

Por outro lado, a violência policial arbitrária, no intuito de dar satisfação à população ou torná-la mais confiante em sua ação, é também perigosa porque desrespeita a lei, dá margem à injustiças, quando não a verdadeiros crimes. $\dot{E}$ evidente que a polícia deve e precisa cumprir o seu dever, que não pode ser confundido com negligência, com receito de ferir direitos humanos, ou arbitrariedade, quando esses direitos serão lesados. A linha divisória entre esses extremos será, em muitos casos, tênue, difícil de ser distinguida. Por isso, é necessário, imperioso mesmo, uma polícia realmente preparada, com reavaliações constantes, que possa ter plena consciência da importância do seu trabalho. E este precisa ser muito mais preventivo, do que repres- 
sivo, o que demanda a instrumentalização adequada em quantidade e qualidade, de efetivos humanos e recursos materiais.

O nosso século vem assistindo ao incremento da delinqüência jovem, especialmente na faixa etária dos 18 aos 30 anos. Os III e IV congressos das Nações Unidas, sobre prevenção de delito e tratamento dos delinqüentes, discutiram o problema, sendo anotados diversos fatores da eclosão e aumento desse desajuste, entre os quais as mudanças sociais e políticas, com aumento das pressões nocivas sobre o meio ambiente, o desenvolvimento industrial, a rápida urbanização, a migração jovem dos campos e pequenas localidades para os grandes centros, fazendo crescer o já alto índice de população nessa faixa etária a qual, se por um lado demonstra grande dose de adaptabilidade, sofre também forte influência do novo estilo de vida, incentivados pelos modernos meios de comunicação, com base no apelo ao mais desenfreado consumismo. Anotaram, ainda, a tendência das legislações em registrar novos tipos de infrações, no intuito de acompanhar as mudanças sociais e tecnológicas, mantendo, entretanto, formas delituosas que já não sensibilizam a comunidade; o crescimento demográfico nos países subdesenvolvidos; a mobilidade social; o câmbio tecnológico e a poluição ambiental, pelos efeitos que causam no comportamento de algumas pessoas.

Podemos dizer que no Brasil estão presentes todos esses fatores. $\mathrm{E}$ um dos grandes, talvez o maior problema brasileiro, é o dos menores e jovens.

Realmente, além do índice de urbanização, considerado um dos mais altos do mundo, o crescimento demográfico alcançou taxas sensíveis até a década de 70; a má distribuição de renda e os altos índices de inflação vêm aviltando o já tão reduzido orçamento familiar; o desemprego cresceu, penalizando multidões; ainda não se fizeram no país as mudanças políticas e sociais requeridas há muito pela população; a legislação penal está obsoleta em muitos pontos; milhares de pessoas migraram do nordeste e centro-oeste para o sul e sudeste, à procura de melhores condições de vida, trazendo problemas insolúveis para as grandes cidades, quanto à moradia, empregos, assistência médica, etc. E neste quadro, temos mais de metade da população brasileira constituída de jovens até 19 anos, a grande maioria dos quais lutando por se realizar, na concorrência feroz por uma vaga na escola e no trabalho.

$\bar{E}$ preciso ter em conta que os jovens hoje querem, desde logo, participar ativamente da vida econômica, social e política do país. Sentem que o mundo, na atualidade, exige muito mais do ser humano, maior participação, aproveitamento dos seus conhecimentos e inteligência e, portanto, a sua fixação, o mais cedo possivel, no posto em que seja útil ou indicado pelas suas aptidões naturais, educação e opção própria. Nessas condições, cresce a responsabilidade do Estado, da família e, em última análise, de cada indivíduo, no sentido de que 
maiores esforços e meios sejam despendidos em prol da criança e do jovem.

Não obstante, muitos se ressentem das transformações experimentadas e vividas pela sociedade e sua personalidade, somática e psiquicamente em formação, faz com que se sintam ante um mundo incoerente, no qual as dissenções políticas e religiosas, o choque dos interesses econômicos, a corrida armamentista com a perspectiva constante da guerra nuclear, o aumento da falta de consciência e ética profissional, de solidariedade humana e responsabilidade cívica, criam descontentamento, descrença e frustração desorientadores. A falta de apoio e orientação, de cursos educacionais e profissionais gratuitos, pois a grande maioria não dispõe de recursos para arcar com as altas taxas escolares, as dificuldades de início de carreira, mesmo quando formados, pode fazê-los perder o interesse em desenvolver todas as suas potencialidades. Esta indiferença ou a revolta vai, muitas vezes, fazê-los voltar contra a sociedade.

Cohen afirma que esses grupos juvenis inadaptados passam a constituir uma sub-área de cultura delitiva, surgindo como uma espécie de solução dos problemas que compartem entre si os jovens das classes menos favorecidas, e seu comportamento representaria uma atitude de defesa ou resistência aos ataques desferidos contra a estabilidade de seu meio. Esta tese, no dizer de Gibbons, obteve amplo reconhecimento, porque tornava inteligiveis muitas realidades.

E uma das análises efetuadas ao redor do estudo de Cohen, realizada por Cloward e Ohlin, denominada teoria dos canais de oportunidades, mostra que os jovens da classe menos favorecida lutam para obter uma condição estável na sociedade. Quando encontram muitas dificuldades para isso e percebem que suas possibilidades de êxito são precárias, surge uma situação de irreconciabilidade entre o que desejam obter e as probabilidades de que o consigam, trazendo uma série de tensões que propiciariam a prática de atos delituosos ${ }^{5}$.

Quando presos, sua ressocialização entre nós não é levada a sério, o que traz para esses jovens uma fixação maior dos papéis representados. E cumprida sua pena a sociedade os repudia, marcando-os como seres diferentes, o que vai dificultar, ou impossibilitar sua reinserção familiar e social.

Neste quadro, não se pode pensar seriamente em reduzir a idade da responsabilidade penal fixada em 18 anos pelo artigo 23 do Código Penal vigente. Tentativas anteriores, como a do Código de 1969, que não chegou a vigorar, mereceram clara repulsa.

5. Cohen, Albert K., "Delinquent Boys". The Free Presse of Glencoe Inc., New York, 1965; Gibbons, Don, "Changing the lawbreaker: the treatment of delinquents and criminals", trađução espanhola de Antonio Garza y Garza, México, 1969, págs. 72 e seguintes; Cloward, Richard A., e Ohlin, Lloyd E., "Delinquency and Opportunity", idem, idem. 
A doutrina moderna entende que, para ser responsabilizado, não basta que a inteligência seja desenvolvida, devendo principalmente ser completo, ou ao menos que tenha progredido, o processo de formação ética do indivíduo. É necessário que a pessoa haja atingido uma idade na qual não-somente possa entender bem o que faz, mas especialmente que esteja em condições de valorar de forma adequada os motivos da vontade, o caráter moral, se não o jurídico, e as conseqüências do fato. $\mathrm{Na}$ idade da evolução, com as alterações físico-psíquicas decorrentes da puberdade e adolescência, quando a sensibilidade às emoções é uma condição quase habitual, e a capacidade de crítica e de autocontrole apresenta-se defeituosa, é muito mais facil o surgimento de sentimentos intensos e dominantes que obscurecem a objetividade do juízo, com freqüente comprometimento da capacidade de entender e de querer.

Assim, no entendimento de Franchini e Introna, não basta que o menor de 18 anos, para ser julgado capaz de entender e querer, tenha adequado desenvolvimento intelectual e de vontade, sendo indispensável, consideradas as características psicológicas da idade evolutiva, que possua suficiente equilíbrio moral, que lhe permita uma segura valoração ética de suas ações ${ }^{6}$.

Entendemos que para o Brasil, nas condições atuais, mesmo a idade de 18 anos estabelecida pela legislação penal é injusta, pois não contamos com institutos próprios para a reabilitação dos jovens adultos delinquientes. Em outros países, mesmo com idade inferior, os jovens são tratados de forma absolutamente individualizada, em sistema e institutos próprios, onde se desenvolve todo um trabalho de correção e aperfeiçoamento físico, psíquico, educacional, moral e profissional, por via de pessoal especializado, a fim de reintegrá-los ao meio social em condiçōes de não mais delinqüir. Entre nós, com o sistema penitenciário absolutamente falido, os jovens são simplesmente incluídos nas prisões comuns dos adultos, não recebendo qualquer tipo de tratamento e cumprem sua pena sob a influência dos mais perigosos, dominados e violentados por verdadeiras quadrilhas que detêm o poder no interior desses institutos.

Se contarmos, além disso, a questão dos menores em situação irregular, isto é, dos menores de 18 anos carenciados de toda a ordem que compõem, em sua maioria, os cinturões de miséria das grandes cidades do país, verdadeiros marginalizados sociais, sem perspectivas e opções, cujos problemas foram mostrados em destaque pela Comissão Parlamentar de Inquérito em relatório encaminhado em abril de 1976 ao presidente da República - sem que as providências aí sugeridas fossem adotadas até hoje - poderemos ver, com clareza, que o problema de maior violência urbana que temos deve ser enfrentado com outras armas que não a pena de morte, torturas ou redução da idade para a responsabilidade penal.

6. Franchini, A. e Introna F., "Delinquenza Minorile", Pádua, 1972, p. 679. 
O problema brasileiro, neste quadro, é de instituições políticas defeituosas e de orientação econômico-social desastrada, que não têm levado em conta as necessidades primordiais do povo em geral, as esperanças dos jovens, a marginalização dos menores e a falta de tratamento dos delinquientes, todos impedidos de viver com dignidade e de contar com a possibilidade de real participação nas decisões que mudam os seus destinos.

E a mudança desse quadro que trará à comunidade a segurança e a tranqüilidade desejadas, acauteladoras dos seus reais interesses.

É preciso não permitir que os menores e jovens carenciados de hoje sejam os marginais de amanhã, como é necessário dar condições aos condenados para que se recuperem. A elevação econômica, social e cultural da imensa classe desfavorecida deste país passa, todavia, e obrigatoriamente, pela sua efetiva participação política, em todos os graus, para que possa realmente sentir a obrigação moral de colaborar e o direito de exigir o cumprimento do que lhe é devido. 